Accur at e frequency measur ement of a submi I I met er wave gyrotron out put usi ng a $\mathrm{f}$ ar-i nf $r$ ar ed I aser as a ref er ence

\begin{tabular}{|l|l|}
\hline 著者 & $\begin{array}{l}\text { I DEHARA T, M TSUDO S, SAI TO S, OGAWA I , } \\
\text { OKAUI MA S }\end{array}$ \\
\hline $\begin{array}{l}\text { j our nal or } \\
\text { publ i cat i on t i t l e }\end{array}$ & Revi ew of Sci ent i f i c I nst r ument s \\
\hline vol une & 74 \\
\hline number & 5 \\
\hline page r ange & $2860-2862$ \\
\hline year & $2003-05$ \\
\hline URL & ht t p: //hdl . handl e. net /10098/1587 \\
\hline
\end{tabular}




\title{
Accurate frequency measurement of a submillimeter wave gyrotron output using a a
}

\author{
T. Idehara, S. Mitsudo, and S. Saito \\ Research Center for Development of Far-Infrared Region, Fukui University, Bunkyo 3-9-I, \\ Fukui 910-8507, Japan \\ 1. Ogawa \\ Cryogenic Laboratory, Faculty of Engineering, Fului University, Bunkyo 3-9-1, Fulaus 910-8507, Japan \\ S. Okajina \\ College of Engineering, Chubus University, Kasugai, Aichi 487-8501, Japan
}

\begin{abstract}
Accurate measurement of gyrotron frequency has been carried out by using a far-infrared (FIR) molecular laser as a reference. Highly stable operation of a FIR laser enables us to make the resolution of frequency measurement so precisely that both the frequency width $\Delta f$ and the frequency fluctuation level of can be studied within the accuracy of $1 \mathrm{kHz}$ or less. When our submillimeter wave gyrotron operates in cw mode, the observed frequency width $\Delta f$ is around 2 $\mathrm{kHz}$ and the fuctuation level $\delta f 10 \mathrm{kHz}$. Such an accurate measurement is a useful tool for development of high quality gyrotrons with stable frequency.
\end{abstract}

\section{MTRODUCTION}

Gyrotron FU series developed in Research Center for Development of Far-Infrared Region, Fukui University (FIR FU) is one of high frequency, step-tunable gyrotrons. The gyrotron series has achieved high frequency operations up to $889 \mathrm{GHz}$ (the corresponding wavelength is $337 \mu \mathrm{m}){ }^{1}$ which is the current world record. The series is being applied to some fields, for example, plasma scattering measurement of a drift wave excited in a plasma of a helical system, ${ }^{2}$ electron spin resonance spectroscopy for material science, ${ }^{3}$ and development of a new medical rechnology which will be applicable for the cancer treatment. ${ }^{4}$ For such applications, especially, for spectroscopy, stabilization of frequency and amplitude are very important. We intend to make our gyrotrons more stable for such a purpose. In addition, applications of gyrotron to spectroscopy in many fields require a very narrow frequency bandwidth. In the past, frequency spectrum of gyrotrons developed for plasma diagnostics has already measured by a heterodyne detection system with a gunn diode as a reference oscillator. ${ }^{5,6}$ The measurement indicates the half value width $\Delta f$ is several tens $\mathrm{kHz}$. However, in this measurement, the bandwidth of a gunn diode is comparable with the observed $\Delta f$. Therefore, the real frequency width of the gyrotron cannot be seen. In order to develop a high stable gyrotron with a narrow frequency bandwidth, the accurate measurement technique of frequency is necessary.

In such a viewpoint, we tried to use a FIR molecular laser as a reference radiation source for the accurate measurement of frequency. Highly stable operation of FIR laser may be useful to measure the frequency of gyrotron output accurately. In this monograph, some preliminary experimen- tal results for the accurate measurement of gyrotron frequency are described.

\section{H. EXPERIMENTAL APPARATUS AND PROGEDURES}

Figure 1 shows the experimental apparatus for accurate measurement of gyrotron frequency using a FIR laser as a reference. Gyrotron FU IV operates in cw mode. The operation frequency is around $295 \mathrm{GHz}$. The output power is around $20 \mathrm{~W}$. It is transmitted through an oversized circular waveguide and fed on a Shottky barrier diode. The real power fed on the diode is $70 \mathrm{~mW}$. The diode operates as a harmonic mixer. After mixing with the signal from a FIR

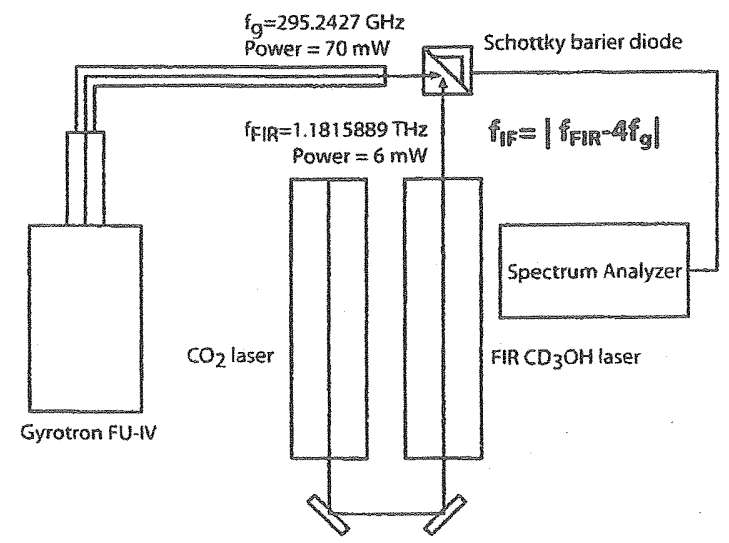

FIG. 1. Block diagram of frequency measurement system using a FIR laser as a reference. 


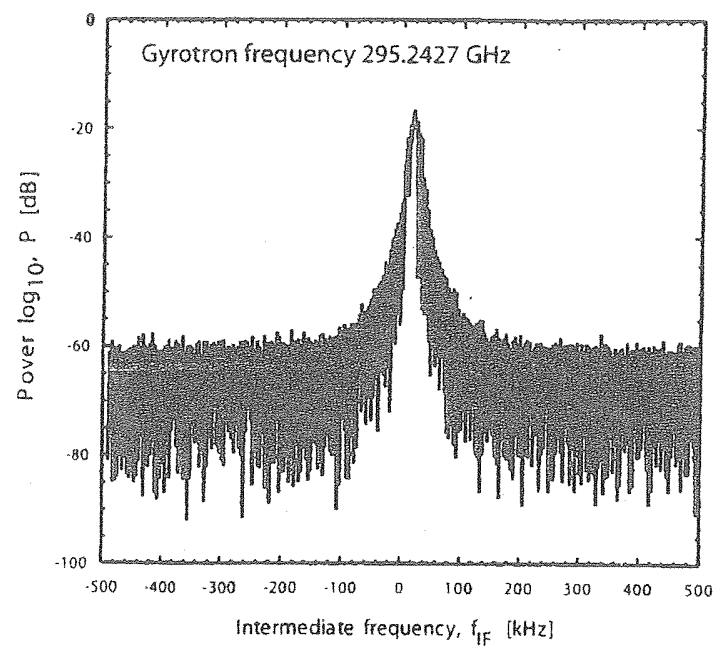

FIG. 2. Frequency spectrum of Gyrotron FU IV output measured by using a synthesizer as a reference. Output frequency of the gyrotron $f_{8}$ $=295.2427 \mathrm{GHz}$

laser, an intermediate (IF) signal is observed on a spectrum analyzer. The If signal includes a frequency component of four times of gyrotron frequency $4 f_{g}$.

Here, we use a $\mathrm{CD}_{3} \mathrm{OH}$ laser excited by a $\mathrm{CO}_{2}$ laser. The frequency $f_{\text {FIR }}$ is $1.1815889 \mathrm{THz}$. And the incident power fed onto the diode is $6 \mathrm{~mW}$.

\section{EXPERIMENTAL RESULTS}

Before measurement of gyrotron frequency using a FIR laser, we tried it by the use of a synthesizer as a reference. Figure 2 shows a result of the measurement. This frequency spectrum is one of the IF signal, which is obtained by the mixing of gyrotron output with 17th harmonic of the synthesizer output. Therefore, the signal with the frequency $f$ $=\left|f_{g}-17 f_{\text {thy }}\right|$ is analyzed. On the frequency spectrum, the half value width $\Delta f$ can be observed. It is seen that $\Delta f$ around $20 \mathrm{kHz}$ or larger. This frequency width of IF signal comes mainly from the frequency width of the synthesizer. In this measurement, both the feature of frequency width and frequency fluctuation of the gyrotron cannot be resolved so accurately.

Figure 3 shows frequency spectra of If signal, which are observed by the use of a FIR laser as a reference. In Fig. $3(\mathrm{a})$, the total sweep time is $10 \mathrm{~ms}$. In this case, the observed frequency width is smaller than $10 \mathrm{kHz}$. A real frequency width of gyrotron output $\Delta f$ is one fourth of it. Therefore, $\Delta f$ is around $2 \mathrm{kHz}$. This value is much smaller than the frequency width of resonant cavity. One possible explanation on the observed frequency width is the effect of technical noise suggested theoretically. ${ }^{7}$

In Fig. 3(b), the total sweep time is $10 \mathrm{~s}$. In the figure, some frequency fluctuations are observed. The width of frequency fluctuation is around $40 \mathrm{kHz}$. So, the real frequency fluctuation of the gyrotron output is $10 \mathrm{kHz}$. Such a frequency fluctuation comes mainly from the fluctuation of high voltage power supplies for an anode and a cathode of electron gun. We should stabilize the power supplies for removing the frequency fluctuation. Highly stable operation of a FIR laser enables us to make an accurate measurement of gyrotron frequency. The frequency resolution of the measurement is much higher than $1 \mathrm{kHz}$. This is a convenient and useful tool for development of high quality gyrotrons with stable frequency.

\section{DISCUSSION}

By the use of a FIR laser as a reference, we have succeeded the highly accurate measurement of gyrotron frequency. The frequency resolution of the measurement is higher than $1 \mathrm{kHz}$. Real frequency width $\Delta f$ and the frequency fluctuation of the gyrotron are around 2 and $10 \mathrm{kHz}$. respectively. Such an accurate measurement of frequency will be a powerful tool for supporting our future development of high quality gyrotron with stable frequency, which is useful for spectroscopy in many fields.

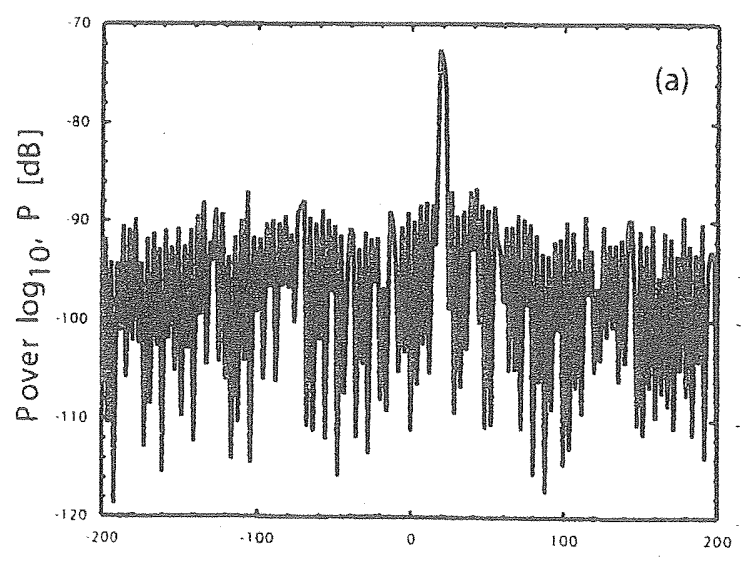

Intermediate frequency, $f_{\text {IF }}[\mathrm{kHz}]$

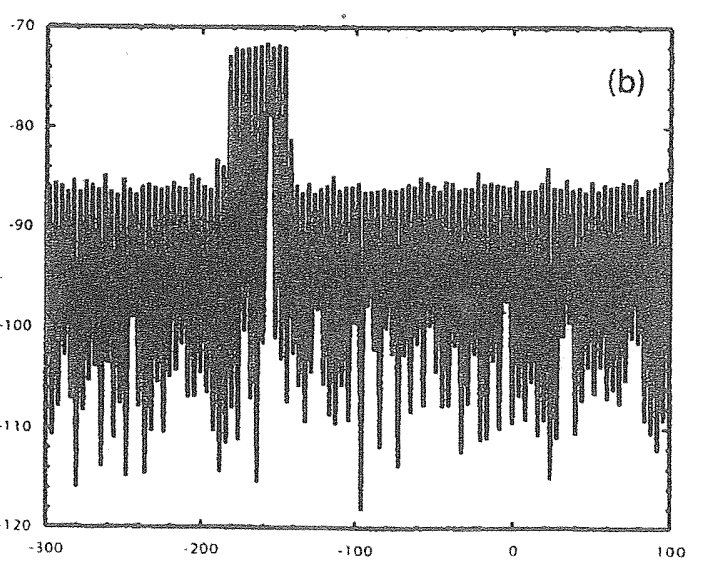

Intermediate frequency, $f_{\text {IF }}[\mathrm{kHz}]$

FG. 3. Frequency spectrum of gyrotron FU IV output measured by using a FIR laser as a reference: (a) full sweep time $10 \mathrm{~ms}$ and (b) $10 \mathrm{~s}$ 


\section{ACRROHEDERMENT}

The study was partially supported by Grant-in-Aid from Japan Society for Promotion of Science (JSPS).

${ }^{1}$ T. Idehara, 1. Ogawa, S. Mitsudo, M. Pereyaslavets, N. Nishida, and $\mathrm{K}$. Yoshida, IEEE Trans. Plasma Sci. 27, 340 (1999)

${ }^{2}$ I. Ogawa, K. Yoshisue, H. Ibe, T. Idehara, and K. Kawahara, Rev. Sci Instrum. 65.1788 (1994).
${ }^{3}$ S. Mitsudo, Aripin, T. Shirai, T. Matsuda, T. Kanemaki, and T. Idehara, Int J. Infraned Millin. Waves 21, 661 (2000).

T. Tarsukawa, A. Doi, M. Teranaka, K. Takashima, E. Goda, T. Idehara, Ogawa, S. Mirsudo, and T. Kanemaki, Int J. Infrared Millim. Waves 21, 1155 (2000)

5. Terumichi et al, Conference Digest, 9h International Conference on infrared and Milimeter Waves, Takarzuka, Japan, October 22-26, 1984, pp. $411-412$.

T. Idehara, T. Tatsukawa, H. Tanabe, S. Matsumoto, K. Kunieda, K. Hemmi, and T. Kanemaki, Phys. Fluids B 3, 1766 (1991).

${ }^{7}$ O. Dumbrais and G. S. Nusinovich, Phys. Plasmas 4 , 1413 (1997) 